\title{
The Prevalence of Hcv Infection among Renal Failure Patients Before Starting Heamodialysis Treatment at Muhimbili National Hospital
}

\author{
Hassan Mwaga, Sima Rugarabamu* and Marcelina Mashurano \\ Department of Microbiology and Immunology, Tanzania
}

*Corresponding author: Sima Rugarabamu, Department of Microbiology and Immunology, Tanzania

Submission: 址 September 08, 2017; Published: 監 November 09, 2017

\begin{abstract}
Background: Hepatitis C virus (HCV) infection has been identified as the major cause of chronic liver disease among patients on chronic heamodialysis (HD), despite the important reduction in risks obtained by testing candidate blood donors for anti-HCV antibodies. Patients receiving maintenance HD therapy are at increased risk for acquiring this infection and have a higher prevalence of HCV than the general population.

Methods: This was a cross - section hospital based study aims to investigate the seroprevalence and associated risk factors for markers of anti-HCV among renal failure patients before starting heamodialysis treatment at Muhimbili National Hospital, Dares Salaam and Tanzania. A total of 120 renal failure patients were recruited into this study from June to July, 2016. Structured questionnaire was used to assess socio-demographic characteristics and the associated risk factors for HCV infection among study participants and the SD Bioline HCV test kit was used to measure anti-HCV antibody levels of the patients.
\end{abstract}

Result: All the participants were tested for HCV infection, whereby Out of 120 participants, 4 tested positive for HCV, which gave the overall seroprevalence of 3.3\%. Males were more prominent in this study (84.2\%) as compared to females, and HCV prevalence sex ratio was 3:1 for males and females. There was no association between history of surgery and blood transfusion with HCV infection.

Conclusion: Although the results suggest that $\mathrm{HCV}$ infection have low prevalence (3.3\%) among renal failure patients before starting heamodialysis treatment at MNH. History of surgery and blood transfusion showed no association with HCV sero-positivity but they are major factors to decrease the prevalence and further prevent new infection from these patients. Further studies to look for genotype and risk factors are recommended.

Keywords: Heamodialysis; Hepatitis c; Prevalence; Muhimbili; Tanzania

\section{Background}

HCV infection is common and associated with significant morbidity and mortality among heamodialysis (HD) patients [1]. Heamodialysis is a trusted intermediate procedure for management of chronic kidney disease (CKD) patients. As such CKD is an immunedeficient state, hence blood borne viral infection particularly HCV pose great risk to patients treated by heamodialysis [2]. A high prevalence of HCV infection in heamodialysis patients has been reported in heamodialysis units since the introduction of heamodialysis therapy. Risk factors such as the number of blood transfusions or duration on heamodialysis. The prevalence of HCV infection in patients undergoing dialysis is greater than that in the general population, suggesting that patients on dialysis may be at higher risk of acquiring HCV infection [3].

The cause for the elevated prevalence of HCV infection in heamodialysis patients may be due to the excessive number of transfusions that these patients are frequently submitted to [4] and since the prevalence increases with the duration of dialysis treatment, there is an indication that the environment itself functions as a vehicle in the dissemination of the virus among the patients in dialysis centers [5].

Morales, et al. [6] in a study concerning the prevalence and incidence of infection by HCV in heamodialysis, observed that $70 \%$ of the positive patients for anti-HCV had undergone blood transfusion. Sayiner, et al. [7] carried out a study in Turkey that compared patients in heamodialysis with those on CAPD treatment. They observed $6.8 \%$ anti-HCV prevalence in CAPD patients, while the heamodialysis patients had a prevalence of $45.7 \%$. The duration of dialysis, the number of transfusions, as well as the number of units of blood received, was the principal factors contributing to the elevated prevalence among heamodialysis patients. In another study conducted in Khartoum, Sudan (2012), showed the prevalence of anti-HCV seropostivity was $8.5 \%$ [8] which is low compared with that reported from heamodialysis centers in Sudan $(23.7 \%)$ 
[9]. However, the prevalence of HCV varies widely from country to country and also from center to center, even within the same country. This can be attributed to variations in the implementation of infection control measures in these heamodialysis units [10].

There is a scarce of information about HCV in Tanzania, and no published data on the seroprevalence of HCV among heamodialysis patients. Thus the magnitude of HCV transmission within heamodialysis units is still unclear and therefore general recommendations for prevention have not been developed. Therefore this study aimed to determine the prevalence of HCV infection among patients undertaking HD treatments at Muhimbili National Hospital, in Tanzania.

\section{Materials and Methods}

\section{Study sample and data collection}

120 patients were randomly selected fromMuhimbili National Hospital. All patients were interviewed for demographic dataand risk factors to HCV infections including history of number of blood transfusion and surgical interventions.

\section{Antibodies screening}

All the subjects were screened for anti HCV antibodiesthird generation test according to the manufactureinstructions (The SDBIO-LINE HCV TEST).

\section{Statistical analysis}

Chi-square test were used to accesses the association between $\mathrm{HCV}$ positivity and variables. Statistical significance was evaluated at 0.05 levels.

\section{Result}

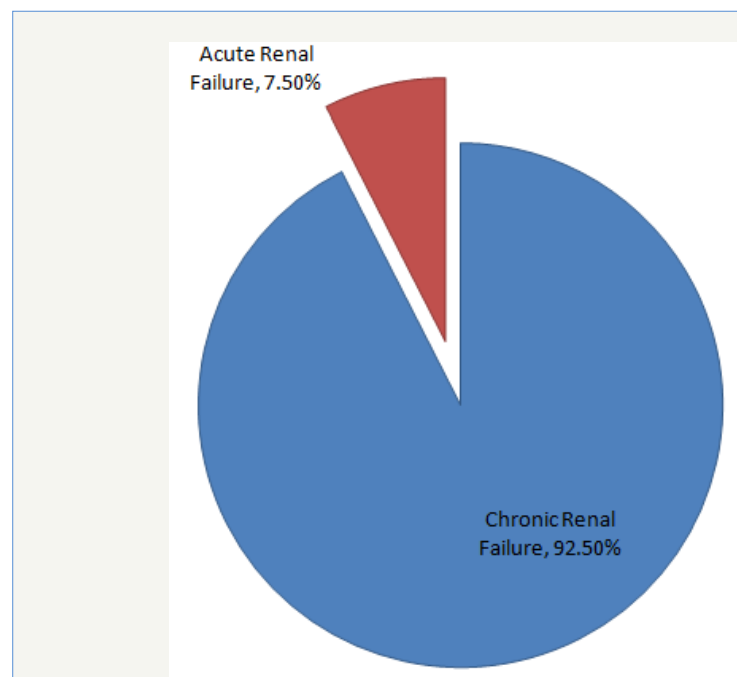

Figure1: Type of Renal Failure.

A total of 120 patients were recruited from May to July, 2016. Among of these 101 (84.2\%) were males and 19 (15.8\%) were females. The overall average age was 51.6 (SD 1.2) years and ranged from 22 to 87 years. Majority of the study participant were in the age group of 55-64, constituting 34(28.3\%). Majority of patients had chronic renal failure 111 (92.5\%) while 9 (7.5) had acute renal failure. Out of 120 patients, 4 tested positive for HCV, giving a seroprevalence of 3.3\%. Among 101 (100\%) males, 3 (2.9\%) were tested positive for HCV, whereas 1 (5.3\%) female out of $19(100 \%)$ tested positive. The difference is not statistically significance (Chisquare $=0.26$; $p$-value $=0.61$ ). There was no association of anti-HCV seroprevalence between age groups and education level with p-value of 0.66 and 0.11 respectively. 24 (20\%) patients had history of blood transfusion while 27 (22.5\%) had history of surgery. The results also show that there is slightly association of blood transfusion and anti-HCV positive results with Chi-square= 7.76; $p$-value $=0.06$, while there is no statistical significance for history of surgery and HCV infection (Chi-square=1.78; p-value=0.18) (Figure 1) (Table 1-3).

Table 1: Sero-prevalence of HCV among study participants 4 (3.3\%) patients out of 120 , were tested positive for ant-HCV.

\begin{tabular}{|c|c|c|}
\hline $\begin{array}{c}\text { SD Bioline Ant-HCV Test } \\
\text { Results }\end{array}$ & Frequency & Percent (\%) \\
\hline Positive & 4 & 3.3 \\
\hline Negative & 116 & 96.7 \\
\hline Total & 120 & 100 \\
\hline
\end{tabular}

Table 2: Sero-prevalence of HCV in relation to socio-demographic characteristics of the study participants.

\begin{tabular}{|c|c|c|c|}
\hline \multirow[t]{2}{*}{ Variable } & \multicolumn{2}{|c|}{ SD Bioline Anti-HCV Test Results } & \multirow[t]{2}{*}{ Total } \\
\hline & Positive & Negative & \\
\hline \multicolumn{4}{|c|}{ Sex of Participants } \\
\hline Male & $3(2.9 \%)$ & $98(97.1 \%)$ & $101(100.0 \%)$ \\
\hline Female & $1(5.3 \%)$ & $18(94.7 \%)$ & $19(100.0 \%)$ \\
\hline \multicolumn{4}{|c|}{ Age Group } \\
\hline$<25$ & $0(0.0 \%)$ & $2(100.0 \%)$ & $2(100.0 \%)$ \\
\hline $25-34$ & $0(0.0 \%)$ & $12(100.0 \%)$ & $12(100.0 \%)$ \\
\hline $35-44$ & $0(0.0 \%)$ & $24(100.0 \%)$ & $24(100.0 \%)$ \\
\hline $45-54$ & $1(3.6 \%)$ & $27(96.4 \%)$ & $28(100.0 \%)$ \\
\hline $55-64$ & $2(5.9 \%)$ & $32(94.1 \%)$ & $34(100.0 \%)$ \\
\hline$>64$ & $1(5.0 \%)$ & $19(95.0 \%)$ & $20(100.0 \%)$ \\
\hline Total & 4 & 116 & 120 \\
\hline
\end{tabular}

Table 3: Risk factors for HCV infection among study participants.

\begin{tabular}{|c|c|c|}
\hline Variable & Frequency & Anti-HCV Positive \\
\hline \multicolumn{3}{|c|}{ Previous Blood Transfusion } \\
\hline Yes & 24 & 3 \\
\hline No & 96 & 1 \\
\hline \multicolumn{3}{|c|}{ History of Surgery } \\
\hline Yes & 27 & 2 \\
\hline No & 93 & 2 \\
\hline Total & 120 & 4 \\
\hline
\end{tabular}




\section{Discussion}

HCV infection has a negative impact on the survival of heamodialysis patients, attributed mostly to HCV-related liver disease and its complications. There is also concern about some adverse outcomes after kidney transplantation in HCV-infected patients. Reduced long term patient and graft survival have been observed in HCV-infected kidney recipients. This is the first study to investigate the seroprevalence among renal failure patients before starting heamodialysis treatment at $\mathrm{MNH}$. The seroprevalence (3.3\%) was low compared with the study which was done in northwest of Tanzania in the general population; the prevalence of HCV was reported to be $18.8 \%[5,10]$ and in other African countries also, for example, $8 \%$ in Kenya and $4.5 \%$ in Sudan [4,3] strict adherence to universal infection control procedures, combined with other preventative measures and regular screening of patients and staff might explain the low seroprevalence of HCV. Males were more prominent in this study (84.2\%) as compared to females, and HCV prevalence sex ratio was 3:1 for males and females. This is consistent with other study conducted $[4,2]$ indicating that the overall seroprevalence among males and females was $66.7 \%$ versus $33.3 \%$, respectively and males comprised a greater proportion $(67.8 \%)$ of all the study participants. There is a significant decrease in GFR with age among men but not among women and therefore the incidence of ESRD seems to be higher in men than women [54], this explains the reason of more men with renal failure than women. The illiterate and age group of 55-64 years were found with the highest prevalence of HCV infection (8.3\% and 5.9\%, respectively); but, age and education level were not associated with HCV infection in this study. Similar findings were reported in Sudan [4,3] where by illiterate had prevalence of $36.7 \%$ and $18.5 \%$ was for age group of 50-60 years.

There is high probability that history of surgery and blood transfusion would be the main risk factors for HCV acquisition among renal failure and heamodialysis patients [5,2]. However, in agreement with other studies done [3-6] there was no association between history of surgery and blood transfusion with HCV infection. It is concluded that results in this study suggest that HCV infection have low prevalence (3.3\%) among renal failure patients before starting heamodialysis treatment at MNH. History of surgery and blood transfusion showed no association with HCV seropostivity but they are major factors to decrease the prevalence and further prevent new infection from these patients.

\section{Acknowledgement}

The authors would like to gratefully acknowledge the kind assistance from Professor Maselle SY (Major supervisor during proposal development) and Dr Majigo M (Head, Department of Microbiology and Immunology at MUHAS) for their help, support, suggestions, encouragement and devotion to this study and their advice and contribution on drafting this work. We would also like to express our sincere thanks to Ms Mashurano M, Mr Zakaria and all staffs and members, Department of Microbiology and Immunology at muhas, for their support during data collection.

\section{References}

1. Svetlozar N (2015) Hepatitis C virus infection in patients on maintenance dialysis. Wolters Kluwer Health Clinical Solution 23(7): 24-25.

2. Pradip B, Kalyan D (2012) Prevalence of Hepatitis B and C among Heamodialysis patients of Tripura, India. EJOHG 2(1): 10-13.

3. Zamani F, Ameli M, Razmjou S, Shakeri R, Amiri A, et al. (2010) Incidence of hepatitis $\mathrm{C}$ infection in patients on hemodialysis: a multicenter study of northern part of Iran. Saudi J Kidney Dis Transpl 21(6): 1169-1171.

4. Mallick NP, Gokal R (1999) Haemodialysis. Lancet 353: 737-742.

5. Allander T, Medin C, Jacobson SH (1994) Hepatitis C transmission in a hemodialysis unit: molecular evidence for spread of virus among patients not sharing equipment. J Med Virol 43(4): 415-419.

6. Morales MF, Lossi JS, Alderete TN, Noli D (1996) Prevalence and seroconversion to HCV in hemodialyzed patients, and epidemiological factors. Transpl Proc 28(6): 3402-3405.

7. Sayiner AA, Zeytinoglu A, Ozkahya M (1999) HCV infection in haemodialysis and CAPD patients. Nephrol Dial Transplant 14(1): 256257.

8. Dahaba M, Gueye S, Ka EF (2014) Trends in hepatitis C infection among hemodialysis patients in Senegal: results of a decade of prevention. Saudi J Kidney Dis Transpl 25(6): 1341-1345.

9. Wiam AA, Christopher WM, Maarten WT (2012) Hepatitis B and C infection in haemodialysis patients in Libya: prevalence, incidence and risk factors. BMC Infect Dis 12: 265.

10. El Amin HH, Osman EM, Mekki MO, Abdelraheem MB, Ismail MO, et al. (2007) Hepatitis C virus infection in hemodialysis patients in Sudan: Two centers' report. Saudi J kidney Dis Transplant 18(1):101-106. 